\title{
Social Media and Older Adults: Understanding Cognitive Training and Social Network
}

\author{
Michael Milovich Jr. \\ Rowan University \\ milovich@rowan.edu
}

\author{
Debra Burleson \\ Baylor University \\ debra_burleson@baylor.edu
}

\begin{abstract}
The literature on technology, cognitive training, and social network of older adults are reviewed through the lens of social inclusion. Technology has enhanced the lives of children to older adults with training, information, and social connections over the internet. Yet, as technology has advanced, those born before the significance of the internet of things (IoT) have minimal exposure to enhance the quality of their lives. Older adults are digital immigrants, those born before personal computers and the IoT became part of everyday life. One might propose that with equal instruction and access to technology, digital immigrants are able to navigate technology regardless of their age. However, research shows that the aging population faces significant training, device, and technical obstacles, which are different from those of digital natives. This review is a foundation for how interventions in older adult speed of processing and social network might support future experimental research.
\end{abstract}

\section{Introduction}

Projections show that by the year 2050, the population of Americans aged 65 and older will grow to 83.7 million [38]. For many older adults, the aging process may include relocating to a nursing home, moving closer to family, or moving in with family. Older adults often significantly lose contact with their network of family and friends once they move to a nursing home facility. They also tend to lose contact with these same groups if they become immobile when living at home. While the familiarities of an older adult's home surroundings provide comfort, there is still a loss of connecting with people, sharing experiences, and stimulating conversations. In one study with approximately 308,000 participants, the results show that individuals with adequate social relationships were
50 percent more likely to survive compared to their counterparts with poor or insufficient social relationships [29]. What is striking about Holt-Lunstad, et al. [29] findings is that a lack of social relationships is as much a health risk as obesity, smoking, and many other known risk factors. To fill the need for social relationships, advances in social technology might improve an older adult's social relationships and increase his or her survival.

From the MacArthur Study, the research focus was on what the authors identify as an orientation toward "successful aging" [46, p. 433]. Demands for improvements in our aging population are increasing. Researchers who have studied successful aging summarize these demands stating, "Our society's core institutions (schools and colleges, workplaces, hospitals, families, and others) were not designed and did not develop to serve a population with the age distribution we are approaching" [47, p. 594].

While not a substitute for the core institutions, social media platforms (i.e., Facebook, Instagram, Twitter, etc.) have the potential to provide older adults with a connection to friends and family. In addition, the internet has helpful information for day-to-day decisionmaking. However, there are unique challenges when the older population-age 65 and older-accesses technology [27]. These technology challenges are beyond those of new learning experienced by the digital natives [33]. The millennial generation, who are digital natives, use computers daily in the ubiquitous age of digital technology [40] and often interact socially and professionally using technology [33]. Older adults are people who were born before the digital age and adopted technology later in life, which fits the category of digital immigrants [40]. These immigrants may not have the resources to access social media, such as a handheld device, internet connectivity, or a resource for technology training to name a few. After addressing these challenges, an older adult may experience issues with internet service, vendor modifications to application security, incessant changes in technology and more. Even so, within all generations, some people 
may choose to have relationships by way of social media and some may not.

Researchers on aging have found that brain exercise [44, 57] and social integration [7] lower the risk of depressive symptoms [10] and dementia in older adults. Furthermore, brain exercise and social integration reduce the risk of cognitive decline $[52,55]$ and healthrelated quality of life issues [57]. The habitual activities found in the use of social media might be a source for developing cognitive speed of processing and social interaction in older adults. Hence, an investigation through the theoretical lens of social inclusion may produce findings that social media has a positive effect on the lifestyle and quality of life decisions made by older adults.

In the design of this project, beyond this current literature review, we envision evidence-based research in the application of interventions that could supplement the social interaction of older adults. This investigation will include a collaboration between academic research and community service where older adults use social media as a supplement to their existing social interaction. The objective is to advance existing social processes through technology innovation. Reengineering or developing new processes may lead to best practices towards a sense of belonging within older adults' everyday lives, regardless of whether the older adult is living an independent life or receiving some form of assisted living.

The following research questions lay the foundation for this investigation: What are the age-relevant adaptable factors in technology that make social media acceptable to older adults? And how is the well-being of an older adult impacted when they experience an increase in social engagement through social media? This literature review lays the foundation for the research objectives and questions we seek to understand.

\section{Theoretical background}

The internet is an extension of personal relationships with both negative and positive consequences [13]. For today's aging population, the internet may be a source for extending the benefits and worries of being socially included in relationships as well. However, internet resources may not be conveniently available for older adults. In a 2016 study, the Pew Research Center finds that 13 percent of Americans do not use the internet and within that percentage 41 percent are over 65 years old [3]. Even so, separate studies on digital social inclusion [37], computer-based cognitive speed of processing training [52], and social network and social integration $[30,7]$ show that each of these areas improve the quality of life in older adults. The following discussion develops a theoretical background for this research. Specifically, this review focuses on social inclusion within the context of acceptance of technology, older adults, and the implications of older adults using technology to enhance their quality of life. It includes discussion on cognitive speed and the challenges that older adults face when using technology.

\subsection{Theoretical lens in social inclusion}

Social inclusion refers to "the extent that individuals, families, and communities are able to fully participate in society and control their own destinies, taking into account a variety of factors related to economic resources, employment, health, education, housing, recreation, culture, and civic engagement" [56, p. 8]. Navigating these areas as an older adult can be challenging and disorienting. Certainly, adults of all ages may experience social inclusion and social exclusion. However, older adults may experience gradual physical challenges while, at the same time, experiencing greater need for healthcare technologies. For example, age, physical disabilities, and partner loss all impact social engagement [45]. Disability includes many subcategories such as losing or diminishing eyesight, muscular control, and mobility. Older adults may be socially excluded because of their physical disabilities, their spouses' disabilities, or because, to society, they are not considered as their families and friends plan future events [50].

Studies suggest that activity is not necessarily fitness, but it includes establishing a sense of worth, social engagement, enjoyment, and productivity [23]. Li and Perkins [32] found that attitudes and a willingness to learn influence learning. Virtual communities may stimulate a sense of worth and social engagement. These communities may reduce the level of isolation, particularly for the older adults who have trouble with disabilities or mobility [9]. In addition to reducing levels of isolation, studies have also found that social networks benefit the health and well-being of individuals [37, 54]. Across gender and race, accounting for levels of disability, results show that there is an association between social engagement and disability. In fact, more socially engaged older adults reported lower levels of disability [19].

Cushman and McLean [16] call for ethical responsibility among information systems (IS) researchers. As the field seeks to develop innovations to improve living conditions, we need to consider those who are the least powerful as well as those who are privileged. Studies also reveal that researchers seeking to improve the quality of life in a target population may potentially harm rather than help, specifically if 
researchers do not consider the full context of the population they seek to help [2]. For example, Cornford \& Klecun-Dabrowska [14] warn that information and communication technology can potentially contribute to isolation when they displace established face-to-face meetings for online discussion groups. If the technology is introduced without understanding the complexities of the integration, the technology can negatively affect the users. In addition, it is important to continue to track users' interactions with the new technology as exclusion is typically not an abrupt change but occurs over time [32].

The IS discipline has developed robust models to predict technology acceptance. One framework example is the Technology Acceptance Model (TAM). Key variables in TAM are the perceived use (PU) of a technology and the perceived ease of use (PEOU) of a technology. Specifically, PU and PEOU focus on important attitudinal factors, which are influenced by a user's inabilities or situational constraints [17]. Using the TAM model, 40 percent of an individual's intention to adopt technology can be determined [39]. Another framework example, Unified Theory of Acceptance and Use of Technology (UTAUT) [53], builds on TAM and explains up to 70 percent of an individual's intention to adopt a technology. The additional explanation involves adding the factors of social influence and facilitating conditions, and four moderating factors of gender, age, expectations, and voluntariness of use [39].

Given that the age of a user affects his or her attitude toward new technology, interaction between a person and technology can either support or deter a person's activity $[31,35]$. Attitudes may also fluctuate over time or fluctuate based on factors such as health, social engagement, and emotions. Peek, et al. [39] note that TAM and UTAUT do not allow for this fluctuation. In addition, Chen and Chan's [11] literature review also found TAM as a useful model, yet with three research limitations when studying older adults: 1) few studies consider age-related factors, 2) studies did not consider causal inference and recommend a longitudinal study, and 3) most participants were from the U.S. or Europe, which is a limited number of cultures.

Renauld and van Biljon's [41] research focus was on older adult acceptance factors, which starts from the time someone is aware of a technology to the time they make full use of that technology and adoption phases, which starts with the purchase of a technology through acceptance or rejection. Understanding the acceptance and adoption of technology by older adults could be used to model their use of mobile phones. Because of their findings, Renauld and van Biljon [41] propose the Senior Technology Acceptance \& Adoption model for mobile technology (STAM). The emphasis of the model is that an older adult user is a different kind of user from that of a younger age user. For example, it is beneficial that an older adult be able to regulate his or her own speed of information processing.

In subsequent research, Chen and Chan [12] studied STAM among older Chinese adults and noted that the price of the technology is often not included. While 68 percent of the variance in technology use was explained, the authors concluded that 32 percent of the variance might be attributed to an unknown variable. In their literature review, Chen and Chan [11] state that older adults understand that innovative technology is beneficial. Yet, older adults believe that they do not have the skills required to use these technologies. Therefore, they will not benefit from them. The researchers conclude that acceptance is strongly tied to ease of use [12].

Building upon TAM-including TAM2 and TAM3, and UTAUT-Merkel, et al. [34] maintain that technology needs to be adopted and used on three levels - the product or the innovation itself, the user's characteristics, and the environmental and contextual framework. As more products include designs to support the needs of the elderly, it becomes important that the IS discipline considers older adult factors. The aging population is not a homogeneous group; therefore, many factors beyond their physical or cognitive change affect the aging process [34].

Textures, pressure, and spatial acuity decrease with age. Therefore, older adults often struggle with technological devices that require tapping small icons, pressing seemingly very small buttons, or using a stylus in addition to right clicking or using a mouse [11].

Peek et al. [39] provide an overview of factors influencing electronic technology acceptance. Knowing that technology acceptance factors fluctuate over time, the authors distinguished between factors in the preimplementation and post-implementation state. Reviewing qualitative, quantitative, and mixed methods research, the researchers targeted participants living in communities with adults who were 60 years of age and older. The authors found 27 factors that influenced electronic technology acceptance and divided these factors into six themes: technology, benefits of technology, need for technology, alternatives to technology, social influence, and characteristics of older adults.

Chen and Chan's [11] review of the 19 studies used for their analysis found that only two studies examined actual usage. Instead, most studies relied on the participants' self-reporting [11]. We believe that reviewing the literature in the area of assessing the technology use of older adults will open rich meaningful approaches for investigating the potential for social inclusion of an aging population. Therefore, within the context of this current review, our definition of social 
inclusion intentionally considers older adults who have often been the least privileged in the era of digital technology. This older adult population, enabled with skills and technologies, may see significant improvement in their health and well-being.

\subsection{Cognitive training}

Research findings show that interventions to address cognitive decline in older adults with mild cognitive impairment have been successful [52]. While cognitive pharmacological approaches have not been effective or have had mixed results [52, 20], cognitive speed of processing training has improved the everyday functional capabilities of older adults $[52,5]$. Today, speed of processing training is a computer-guided drill of brief nonverbal exercises where the trainee progresses through discovery and identification that gradually increases to reach a target speed and difficulty level [5]. Hence, Wolinsky et al. [57] found in their longitudinal study of 1,804 participants that two years after training, those who underwent speed of processing training were less likely to have extensive health related quality of life decline when compared to their control group. In addition, when compared to memory and reasoning training interventions in Wolinsky et al.'s [57] study, those involved in training for five years, including processing speed, working memory, and intervention reasoning (i.e., fluid cognitive ability [36]), were all successful at reducing health-related quality of life decline.

As a practical example, in a 10-year study on driving cessation in older adults, findings show that adults who underwent reasoning training were 55 percent less likely to quit driving. Moreover, adults who underwent speed of processing training were 49 percent less likely to stop driving - a percentage that increased to 70 percent when additional speed of processing training was administered [44]. These findings are significant as they further support the literature that older adults who cease driving may experience depression, health decline, and lack of social engagement. Also, these findings support the Wolinsky et al. [57] findings that health-related quality of life is a result of speed of processing training in older adults. The position that cognitive ability from memory and reasoning training enhances health-related quality of life and driving cessation is true as well; however, the time needed to realize the benefit of memory and reasoning interventions is longer than speed of processing training. The quick fluid cognitive ability increase, through speed of processing training, may encourage older adults in the use of technology. That is, a technology focus that encourages older adults in their cognitive abilities could potentially reduce depression and health-related quality of life issues in their lives.

The designs for assessment and involvement in training have progressively moved from labor-intensive activities (i.e., flash cards, puzzles, manual writing/drawing exercises, video simulations, etc.) to digital formats. Computer-based training programs, once distributed through floppy diskette and compact disk (CD) increased the accessibility to training material. Today, computer-based training programs over the internet have not only increased distribution in an anytime, anywhere, any device society; in addition, they provide a means for scoring and recording instantaneous feedback of training results. Over time, easy access and quick assessments are principally due to collaborative interaction of downloadable applications over the internet or interaction provided from cloudbased applications. Of equal importance is the increased availability of cognitive training applications with an emphasis on maintaining brain activity. For example, commercial applications, aimed at self-aware consumers looking to maintain fluid cognitive awareness, claim cognitive improvement with daily use. In addition, applications developed for health care professionals, educators, and researchers for assessment or intervention founded on test-retest evidence-based claims.

Just as the distribution of training has changed, so have the devices used to access information. Mobile technology devices have transformed the end-users' access to information. Gartner, a leading worldwide practitioner research firm that makes recommendations about technology to business, predicts that by 2018 fifty percent of all online activity will involve access through tablets or smartphones. In emerging countries, mobile devices will be the only access used and in developed countries, multiple devices will be the norm with mobile devices as the first choice [43]. Gartner further reports that tablets are the fastest growing computer device for users [43]. The Pew Research Center, in their own study on technology ownership, indicates that 45 percent of adults in America own tablet computers, up from only 3 percent in 2010. The study shows that this is the largest increase among digital devices (e.g., cellphone, smartphone, desktop/laptop, tablet computer, game console, MP3 player, e-book reader) [4].

Our literature review combines the value of older adult speed of processing interventions and tablet technology integration. Moreover, the initial theory introduced in 1974 suggests that a slowing of cognitive speed of processing reduces one's cognitive ability during aging [8]. Subsequent research supports this theory and further reveals that speed of processing degeneration accounts for a significant percentage of cognitive decline in aging over time $[48,20]$. Whereas, 
memory and reasoning training targets the improvement of cognitive performance, speed training targets the practice of tasks to increase the speed of processing information. Furthermore, extant results show that education and age are not related benefits of training; however, those who have the most room to improve basic fluid cognitive ability benefit the most from speed training [5].

Additionally, computer-based speed of processing training on tablet devices is the chosen intervention for this current research. The popularity of tablet devices over other types of devices seems to be appropriate for routine tasks that may easily become habitual for older adults. Against the background of a low-risk training protocol, accessible application, and popular device technology, we assert the following proposition:

Proposition: An older adult involved in computerbased speed of processing training will experience greater cognitive promptness when processing tasks with information.

\subsection{Social network and social integration}

Cognitive and functional loss in older adults decreases social interaction and physical activity, which negatively affects quality of life $[22,57]$. Some studies in the 1990s report that there are no findings that social network [1] and social engagement [28] are a concern for reducing cognitive ability. However, recent studies produce findings that social relations from both social network [7] and social integration or engagement [30, 7] have a protective effect on cognition. Béland et al. [7] define social network "by their structure (types and number of social ties, proximity of relationship) and function (frequency of contact, reciprocity, social engagement)" and social integration as "community such as belonging to neighborhood or religious groups or nongovernmental organizations" (p. 323). Finally, social engagement is how one feels he or she has helped or feels useful to a family member or friend [7].

Scholars have found that participation in frequent social connections and social activities tend to prevent cognitive decline [6], and that a rich social network with creative education or interactive activities may decrease dementia risk [55]. Whereas, social engagement findings have been interpreted as reducing the risk of cognitive decline $[55,49,30,15]$, even after adjusting for age and education, social disengagement findings have been interpreted as a possible risk [6, 15]. Interestingly, some researchers interpret the benefits of social interaction through findings that the frequency of relationships can either be positive or negative (social demand or social conflict) $[30,49]$.
Older adults with more frequent contacts in larger networks relate more positively and retain better cognitive health $[15,30]$. Contacts in these investigations are defined as phone calls or visits from people that the older adult keeps in touch with [30]. Holtzman et al. [30] found that frequent contacts in larger networks and the level of emotional support related positively to cognitive health. Moreover, other researchers find that the size of a network is not always as important as having a meaningful and supportive exchange within a network [24]. For example, a person who has no social ties is two times more likely to experience cognitive impairment than one who has only five or six social ties [6].

The following case illustrates a real-world application of the need for social network and social integration aside from the cognitive advantages. In a 5year study on the effect of older adult widowhood, researchers investigated formal and informal social roles. In the researcher's definitions a formal social role (social integration) includes attending meetings, participating in religious events, and committing time to volunteer work. An informal social role (social network) includes interacting over the phone and socially with friends. While a spousal loss did not increase one's social integration, the loss was instrumental in increasing one's social network. A significance of this research is that an older adult does not tend to pursue an active social participation replacement. Findings reveal that older adults tend to rely on and connect with lifelong relationships for stability in social relationships [51]. Social technology can help older adults maintain those relationships.

While necessities are the basics of life, sometimes a simple contribution to an older adult's day is grasping the concept of a computer application [42]. Technology has become valuable and sometimes a necessity in the personal life of most people living in developed countries. Technology connects people, occupies time, and provides access to information [26]. Researchers are finding that the importance of technology extends into the life of older adults as well. Older adults do not know about the many technologies available to them; they are resistant to using technology or they are more concerned about what seems to be the complexity of technology [25]. Yet, there is little participation opportunities for the older adults on how technology can address their social needs $[26,9]$.

Hasan \& Linger's [26] two-year study involved conducting computer classes in two older adult care facilities. The focus was addressing the preferences of the participants in weekly classes. The technology was a mix of second-hand equipment connecting to $\mathrm{Wi}-\mathrm{Fi}$ and personal devices (e.g., laptops, iPads). The adult's choice of technology activity and device was what 
interested him or her and was constant with his or her desires throughout the training. The salient point in the research findings is that an older adult was most gratified when he or she used technology for what he or she wanted to accomplish (i.e., email, video call, word processing, etc.). There was little interest in social media, but a few set up a Facebook account for family connections.

Hakkarainene's [25] research focuses on social representation theory as verbal and behavioral expresses about something as a social group, in this case, older adults in the use of technology. Within their representation, technology is one of four dichotomous senses of two branches of something the adult is not familiar with, that is, (1) it is either useful or useless, (2) creates freedom or dependence, (3) use is risky or use is not risky, and (4) is similar too or different from. These senses involve an understanding that the older adult develops from his or her own observations or images of technology gathered from family and friends, work history, lifestyle, and other society inputs. Hakkarainene's interpretation of the findings is that older adults should have social representation programs developed to inform, train, and support them as equal citizens of technology in a digital world.

Hence, research on the use of current handheld device technology found that older adults had greater acceptance of the digital world with tablet technology. The use of iPads created a sense of social interaction and an increase in overall technology ability [18]. The inference found in the three investigations discussed above is that appropriate information, training, and modern day devices revealed positive and significant results with older adults. While these projects were not a direct study of social media with older adults, there was some interest in social media. Delello and McWhorter [18] noted that there was social interaction with the devices among the older adults they studied, which created a positive impression about technology in that social group.

The expectation is that in an older adult's lifetime he or she changes from a lifestyle of engaging and demanding cognitive activities. Additionally, during aging, one's biological changes may put restrictions on cognitive function stimulation through physical health and reduce motivation to engage in activities [28]. Because of a reduction in demand for cognitive activities and restrictive physical activity, nonphysical methods of maintaining fluid cognitive ability need to be the focus for older adults.

In considering our future investigation, assessing participants and involving them in speed of processing interventions is an appropriate first step. We find that one's education is not a factor in the task of processing information in older adults [5] and that there is a defined ceiling when speed of processing is sufficient for fluid cognitive ability [44, 5]. That said, our future investigation has relevant measures for assessing the validity of participant involvement, since our study proposition is to understand one's ability to engage in information tasks. In addition, to accomplish technology tasks some researchers have found that older adults favor tablet technology as a personal device.

For the purpose of our investigation, social network refers to the people that a participant has a personal relationship with and keeps in touch with regularly over a six-month period [30]. We believe this is important since researchers have shown that social network and social engagement are an element in the quality of life of older adults.

\section{Proposition: Older adults will use social media on tablet devices to connect with their social network.}

\subsection{Summary}

Research findings reveal that physical, social, and mental activities are evidence for the prevention of dementia late in life [21]. While some activities, such as physical ones, become more difficult to maintain over time, speed of processing interventions continue to act as deterrents to reduced cognitive ability [52]. It seems appropriate that the body of knowledge include findings on how speed of processing interventions may increase the use of social media by older adults.

Face-to-face communication is important for an intimate relationship. Yet, while virtual communication through social media may not be a substitute for an intimate relationship [13], social media may continue a relationship or help restore a relationship. Relationships also change when older adults move or are separated from family and friends due to illness [13]. Social media might be a substitute that allows for relationships when separation occurs, due to an adult child's mandated independence or through the separation of an uprooted friend.

Social media, as a tool, may provide a form of social integration and cognitive speed training needed to improve an older adult's quality of life. Similarly, we have begun to understand the value of tablet technology for older adults. The simplicity of use, size, and integration with cognitive exercises and social media may be the combination needed for a larger number of older adults to use technology.

In this literature review, we sought to understand if speed of processing intervention is a catalyst for helping older adults consider the use of social media and, in addition, if an approach for greater social inclusion through technology will have a positive and significant 
effect on an older adult's sense of social engagement. Finally, we wanted to understand if a commercially available end-user device might be available that older adults would begin to feel comfortable using. We believe that this review has provided reasonable evidence in the literature to develop propositions for future research.

\section{Implications}

Social inclusion involves intentional actions and processes. It also anticipates obstacles that might impede users from accessing important and necessary resources, like technology. While technology might be easy to access for some, an older adult's station in life might potentially make accessing technology difficult. As discussed in our review, many of the studies depend on user self-reports. We believe that there is much rich data beyond self-reports that will provide important insights and significantly assist older adults as they continue to use technology.

$\mathrm{Li}$ and Perkins [32] conclude their study about the implications of technological developments on the elderly by stating that society has a responsibility to encourage technological learning in the elderly population. In their summary, the authors remind us that technologies are becoming more advanced and more sophisticated at a time when our aging population is increasing.

As our aging population increases, demand for technologies that improve the quality of life, health, and well-being of the population will increase. This review has exposed the potential for a study on older adult quality of life through speed of processing, social network, and social integration. The aging population, like other subgroups of the population, is complex and heterogeneous. In addition, as our population grows older and lives longer, we are living in a world with a higher mean age. As seminal research to address that point, the MacArthur Study refers to the need for successful aging [46], and it is in this mindset that we position future research. There is still much to study about our aging population and their use of technology, since both are changing every day.

\section{Conclusion}

Technology has improved our lifestyles, making our friends, colleagues, and family accessible at any time no matter where we live or work in the world. We live in a world that requires connectivity, and we are motivated to learn early in life how to navigate these technologies because of individual needs, desires, and social demands. Yet, we also realize that for the aging population, the skills that were once second nature may become extremely difficult. This paper reviewed the value of speed of processing training, challenges that the older adults face as they use technologies, and how social inclusion might provide significant insights. Rather than advocating for the traditional methods of teaching and exploring technology, we propose that the IS discipline first needs to understand how an older adult might interact with technology and improve the quality of their life.

Past studies reveal findings on the significance of cognitive speed, social interaction, and social networks. In addition, some investigations use interventions that reduce the risk of cognitive decline and increase quality of life. We believe these findings may adapt to an older adult's use of social media and open opportunities for managing everyday functional capabilities as well.

This review has not considered the copious extant research findings regarding older adult cognitive development and the same is true for social network. Our discussion herein is not denying the validity of other approaches. Rather, our review is laying the foundation for incremental finding to the body of knowledge. We believe that this knowledge will grow exponentially as results from future studies improve the lives of older adults.

\section{Future research}

As evident by our discussion, we are designing an experimental research project for introducing social media to older adults. This literature review is part of the scholarly structure for a manuscript to document a field investigation. We have a parsimonious research design for an exploratory investigation to help us reduce rival explanations in our future findings. Potentially, new understandings from our near-term future research will promote an advancement in design to include additional variables and complexities for understanding the aging population in future studies.

\section{References}

[1] M.S. Albert, K. Jones, C.R. Savage, L. Berkman, T. Seeman, D. Blazer, and J.W. Rowe, "Predictors of Cognitive Change in Older Persons: MacArthur Studies of Successful Aging”, Psychology and Aging, 10(4), 1995, pp. 578-589.

[2] A.D Andrade and B. Doolin, "Information and Communication Technology and the Social Inclusion of Refugees", MIS Quarterly, 40(2), 2016, pp. 405-416.

[3] M. Anderson and A. Perrin, " $13 \%$ of Americans Don't Use the Internet. Who are They?", Pew Research Center, http://www.pewresearch.org/fact-tank/2016/09/07/some- 
americans-dont-use-the-internet-who-are-they/, 2016, Retrieved January 29, 2017.

[4] M. Anderson, "Technology Device Ownership: 2015", Pew Research Center, http://www.pewinternet.org/2015/10 /29/technology-device-ownership-2015/, 2015, Retrieved June 5, 2017.

[5] K. Ball, J.D. Edwards, and L.A. Ross, "The Impact of Speed of Processing Training on Cognitive and Everyday Functions", The Journals of Gerontology Series B: Psychological Sciences and Social Sciences, 62(1), 2007, pp. 19-31.

[6] S.S. Bassuk, T.A. Glass, and L.F. Berkman, "Social Disengagement and Incident Cognitive Decline in Community Dwelling Elderly Persons", Annals of Internal Medicine, 131(3), 1999, pp. 165-173.

[7] F. Béland, M.V. Zunzunegui, B. Alvarado, A. Otero, and T. del Ser, "Trajectories of Cognitive Decline and Social Relations", The Journals of Gerontology Series B:

Psychological Sciences and Social Sciences, 60(6), 2005, pp. 320-330.

[8] J.E. Birren, A.M. Woods, and M.V. Williams, "Behavioral Slowing with Age: Causes, Organization, and Consequences of Slowing", In L.W. Poon (Ed.), Aging in the 1980s: Psychological Issues, pp. 293-308. Washington, DC: American Psychological Association, 1980.

[9] E. Blit-Cohen and H. Litwin, "Elder Participation in Cyberspace: A Qualitative Analysis of Israeli Retirees", Journal of Aging Studies, 18(4), 2004, pp. 385-398.

[10] G.S. Brewster, L. Peterson, R. Roker, M.L. Ellis, and J.D. Edwards, "Depressive Symptoms, Cognition, and Everyday Function Among Community-Residing Older Adults", Journal of Aging and Health, 29(3), 2016, pp. 367388.

[11] K. Chen and A.H.S. Chan, "A Review of Technology Acceptance by Older Adults", Gerontechnology, 10(1), 2011, pp. 1-12.

[12] K. Chen and A.H.S. Chan, "Gerontechnology Acceptance by Elderly Hong Kong Chinese: A Senior Technology Acceptance Model (STAM)", Ergonomics, 57(5), 2014, pp. 635-652.

[13] J. Climo, "Images of Aging in Virtual Reality: The Internet and the Community of Affect", Generations, 25(3), 2001, pp. 64-68.

[14] T. Cornford and E. Klecun-Dabrowska, "Social Exclusion and Information Systems in Community Healthcare", In M. Korpela, R. Montealegre, and A. Poulymenakou (Ed.), Organizational Information Systems in the Context of Globalization, pp. 291-305, Springer US, 2003.
[15] V.C. Crooks, J. Lubben, D.B. Petitti, D. Little, and V. Chiu, "Social Network, Cognitive Function, and Dementia Incidence Among Elderly Women", American Journal of Public Health, 98(7), 2008, pp. 1221-1227.

[16] M. Cushman and R. McLean, "Exclusion, Inclusion, and Changing the Face of Information Systems Research", Information Technology \& People, 21(3), 2008, pp. 213-221. [17] F.D. Davis, "Perceived Usefulness, Perceived Ease of Use, and User Acceptance of Information Technology", MIS Quarterly, 13(3), 1989, pp. 319-340.

[18] J.A. Delello and R.R. McWhorter, "Reducing the Digital Divide Connecting Older Adults to iPad Technology", Journal of Applied Gerontology, 36(1), 2017, pp. 3-28.

[19] C.F.M. de Leon, T.A. Glass, and L.F. Berkman, "Social Engagement and Disability in a Community Population of Older Adults the New Haven EPESE", American Journal of Epidemiology, 157(7), 2003, pp. 633-642.

[20] S.I. Finkel, J.E. Mintzer, M. Dysken, K.R.R. Krishnan, T. Burt, and T. McRae, "A Randomized, Placebo-controlled Study of the Efficacy and Safety of Sertraline in the Treatment of the Behavioral Manifestations of Alzheimer's Disease in Outpatients Treated with Donepezil", International Journal of Geriatric Psychiatry, 19(1), 2004, pp. $9-18$.

[21] L. Fratiglioni, S. Paillard-Borg, and B. Winblad, "An Active and Socially Integrated Lifestyle in Late Life Might Protect Against Dementia", The Lancet Neurology, 3(6), 2004, pp. 343-353.

[22] J.J. Gallo, R. Schoen, and R. Jones, "Cognitive Impairment and Syndromal Depression in Estimates of Active Life Expectancy: The 13-year Follow-up of the Baltimore Epidemiologic Catchment Area Sample", Acta Psychiatrica Scandinavica, 101(4), 2000, pp. 265-273.

[23] T.A. Glass, C.M. de Leon, R.A. Marottoli, and L.F. Berkman, "Population Based Study of Social and Productive Activities as Predictors of Survival among Elderly Americans", BMJ, 319(7208), 1999, pp. 478-483.

[24] C.C. Godinho, J. Rinaldi, J. Varela, D. Onyszko, C. Kohler, A.L. Camozzato, and M. Chaves, "The Role of Social Network in Dementia Incidence: Porto Alegre Longitudinal Aging (PALA) Study", Alzheimer's \& Dementia, 6(4), 2010, S450.

[25] P. Hakkarainen, " No Good for Shoveling Snow and Carrying Firewood': Social Representations of Computers and the Internet by Elderly Finnish Non-users", New Media \& Society, 14(7), 2012, pp. 1198-1215.

[26] H. Hasan and H. Linger, "Enhancing the Wellbeing of the Elderly: Social Use of Digital Technologies in Aged Care", Educational Gerontology, 42(11), 2016, pp. 749-757. 
[27] D. Hawthorn, "Possible Implications of Aging for Interface Designers", Interacting with Computers, 12(5), 2000, pp. 507-528.

[28] C. Hertzog, D.F. Hultsch, and R.A. Dixon, "On the Problem of Detecting Effects of Lifestyle on Cognitive Change in Adulthood: Reply to Pushkar et al. (1999)", Psychology and Aging, 14(3), 1999, pp. 528-534.

[29] J. Holt-Lunstad, T.B. Smith, and J.B. Layton, "Social Relationships and Mortality Risk: A Meta-analytic Review", PLoS Med, 7(7), 2010, e1000316.

[30] R.E. Holtzman, G.W. Rebok, J.S. Saczynski, A.C. Kouzis, K.W. Doyle, and W.W. Eaton, "Social Network Characteristics and Cognition in Middle-aged and Older adults", The Journals of Gerontology Series B: Psychological Sciences and Social Sciences, 59(6), 2004, pp. 278-284.

[31] M.P. Lawton and E.M. Brody, "Assessment of Older People: Self-maintaining and Instrumental Activities of Daily Living", Gerontologist, 9(3), 1969, pp. 179-186.

[32] Y. Li and A. Perkins, "The Implications of Technological Developments on the Daily Life of the Elderly", Technology in Society, 29(3), 2007, pp. 361-368.

[33] J.C. Meister and K. Willyerd, "Mentoring Millennials", Harvard Business Review, 88(5), 2010, pp. 68-72.

[34] S.E. Merkel, P.E. Enste, J.O. Hilbert, K. Chen, A. Chan, and S.U. Kwon, Technology Acceptance and Aging, Kwon, S.(Hg.), Gerontechnology 2, 2016.

[35] H. Mollenkopf and J. L. Fozard, "Technology and the Good Life: Challenges for Current and Future Generations of Aging People", Annual Review of Gerontology and Geriatrics, 23, 2003, pp. 250-279.

[36] P.C. Opitz, I.A. Lee, J.J. Gross, and H.L. Urry, "Fluid Cognitive Ability is a Resource for Successful Emotion Regulation in Older and Younger Adults", Frontiers in Psychology, 5(609), 2014, pp. 45-57.

[37] T.N. Ordonez, M.S. Yassuda, and M. Cachioni, "Elderly Online: Effects of a Digital Inclusion Program in Cognitive Performance", Archives of Gerontology and Geriatrics, 53(2), 2011, pp. 216-219.

[38] J.M. Ortman, V.A. Velkoff, and H. Hogan, "An Aging Nation: The Older Population in the United States", Washington, DC: US Census Bureau, 2014, pp. 25-28.

[39] S.T. Peek, E.J. Wouters, J. van Hoof, K.G. Luijkx, H.R. Boeije, and H.J. Vrijhoef, "Factors Influencing Acceptance of Technology for Aging in Place: a Systematic Review", International Journal of Medical Informatics, 83(4), 2014, pp. 235-248.

[40] M. Prensky, "Digital Natives, Digital Immigrants Part 1”, On the Horizon, 9(5), 2001, pp. 1-6.
[41] K. Renaud and J. Van Biljon, "Predicting Technology Acceptance and Adoption by the Elderly: A Qualitative Study", Proceedings of the 2008 annual research conference of the South African Institute of Computer Scientists and Information Technologists on IT research in developing countries: Riding the wave of technology, ACM, 2008, pp. 210-219.

[42] G. Reynolds, "Uncovering New Ways to Help People Stay Comfortable and Connected in Their Older Years", Blog of University of Wollongong, The Stand, http://stand. uow.edu.au/growing-old-gracefully/, 2017, Retrieved March 24,2017

[43] J. Rivera and R. van der Meulen, "Gartner Says by 2018, More Than 50 Percent of Users Will Use a Tablet or Smartphone First for All Online Activities", Gartner, http://www.gartner.com/newsroom/id/2939217, 2014, Retrieved June 5, 2017.

[44] L.A. Ross, S.A. Freed, J.D. Edwards, C.B. Phillips, and K. Ball, "The Impact of Three Cognitive Training Programs on Driving Cessation Across 10 Years: A Randomized Controlled Trial", The Gerontologist, gnw143, 2016.

[45] A.L. Rosso, J.A. Taylor, L.P. Tabb, and Y.L. Michael, "Mobility, Disability, and Social Engagement in Older Adults", Journal of Aging and Health, 25(4), 2013, pp. 617637.

[46] J.W. Rowe and R.L. Kahn, "Successful Aging”, The Gerontologist, 37(4), 1997, pp. 433-440.

[47] J.W. Rowe and R.L. Kahn, "Successful Aging 2.0: Conceptual Expansions for the 21st Century", Journal of Gerontology Series B: Psychological Sciences and Social Sciences, 70(4), 2015, pp. 593-596.

[48] T.A. Salthouse, "Speed Mediation of Adult Age Differences in Cognition", Developmental Psychology, 29(4), 1993, pp. 722-738.

[49] T.E. Seeman, T.M. Lusignolo, M. Albert, and L. Berkman, "Social Relationships, Social Support, and Patterns of Cognitive Aging in Healthy, High-Functioning Older Adults: MacArthur Studies of Successful Aging", Health Psychology, 20(4), 2001, pp. 243-255.

[50] P. Tsakloglou and F. Papadopoulos, "Aggregate Level and Determining Factors of Social Exclusion in Twelve European Countries", Journal of European Social Policy, 12(3), 2002, pp. 211-225.

[51] R.L. Utz, D. Carr, R. Nesse, and C.B. Wortman, "The Effect of Widowhood on Older Adults' Social Participation an Evaluation of Activity, Disengagement, and Continuity Theories", The Gerontologist, 42(4), 2002, pp. 522-533.

[52] E.G. Valdes, R. Andel, J.J. Lister, A.A. Gamaldo, A.L.H. Bush, and J.D. Edwards, "The Efficacy of Cognitive Speed of Processing Training Among Older Adults with 
Psychometrically-defined Mild Cognitive Impairment", Alzheimer's and Dementia: The Journal of the Alzheimer's Association, 12(7), 2016, pp. 426-427.

[53] V. Venkatesh, M.G. Morris, G.B. Davis, F.D. Davis, "User Acceptance of Information Technology: Toward a Unified View", MIS Quarterly. 27(3), 2003, pp. 425-478.

[54] B. Wang, P. He, and B. Dong, "Associations Between Social Networks, Social Contacts, and Cognitive Function Among Chinese Nonagenarians/Centenarians", Archives of Gerontology and Geriatrics, 60(3), 2015, pp. 522-527.

[55] H. Wang, A. Karp, B. Winblad, and L. Fratiglioni, "Late-life Engagement in Social and Leisure Activities is
Associated with a Decreased Risk of Dementia: A Longitudinal Study from the Kungsholmen Project", American Journal of Epidemiology, 155(12), 2002, pp. 10811087.

[56] M. Warschauer, Technology, and Social Inclusion: Rethinking the Digital Divide, MIT Press, 2003.

[57] F.D. Wolinsky, F.W. Unverzagt, D.M. Smith, R. Jones, A. Stoddard, and S.L. Tennstedt, "The ACTIVE Cognitive Training Trial and Health-related Quality of Life: Protection that Lasts for 5 Years", The Journals of Gerontology Series A: Biological Sciences and Medical Sciences, 61(12), 2006, pp. 1324-1329. 